\title{
A Educação Física, o docente e a escola: concepções e práticas pedagógicas
}

CDD. 20.ed. 371.1

796.017
Nestor BERTINI JUNIOR*
Elvira Cristina Martins TASSONI*
*Pontifícia Universidade Católica - Campinas.

\section{Resumo}

Este artigo baseia-se em um estudo que investigou de que maneira as mudanças ocorridas na área da educação fisica vêm marcando a concepção do professor e a sua prática pedagógica. Trata-se de pesquisa qualitativa, investigando quatro professores de educação física, selecionados segundo os seguintes critérios: atuar no ensino público em escolas diferentes, ter tempo de formado e de docência diferentes entre eles. Os dados foram coletados através de entrevistas recorrentes. Este procedimento baseia-se em algumas etapas de entrevistas seguida de categorização dos dados após cada uma delas. Os sujeitos participam ativamente completando, alterando e esclarecendo informações, interagindo com o pesquisador. Os resultados possibilitaram identificar que as mudanças ocorridas na área da educação física, na visão dos docentes investigados, influenciam desde os aspectos relacionados à formação inicial, passando pelas condições de trabalho na escola e a forma de organizar a prática pedagógica, influenciando na valorização da área, bem como do docente.

Palavras-chave: Práticas pedagógicas; Formação do educador; Educação física; Entrevistas recorrentes.

\section{Introdução}

Historicamente, as atividades físicas sempre estiveram em um patamar inferior em relação às atividades, reconhecidamente, intelectuais. Nesse sentido, BETTI ${ }^{1}$ destaca dois aspectos que contribuem para a desvalorização da educação física. O primeiro referese à maneira simplificada em que a área é vista, não se identificando e nem reconhecendo os conhecimentos que lhes são específicos. O segundo refere-se à ideia de que há familiaridade intensa entre as pessoas e as práticas corporais, dando a falsa impressão de que a área e o profissional seriam quase que dispensáveis, inclusive no ambiente escolar.

Atualmente, ruas e avenidas estão sempre cheias de pessoas caminhando, principalmente nas épocas mais quentes do ano, em que os corpos ficam mais expostos. Como nos mostra o documento da Secretaria Estadual de Educaçãa ${ }^{2}$, somos bombardeados por imagens que, por muitas vezes, nos levam a buscar padrões de beleza possíveis para poucos, levando algumas pessoas a pagar altos preços não só do ponto de vista financeiro, mas também da saúde, fazendo uso de medicamentos, energéticos, alimentos, cirurgias e excedendo-se em academias colocando em risco a própria saúde com substâncias proibidas ou inadequadas. Observamos uma supervalorização do trabalho com o corpo fora da escola em detrimento do trabalho dentro dela. Há uma diferença acentuada entre os profissionais das escolas e os que atuam fora dela, em clubes e academias, por exemplo. Temos de um lado, um profissional e área com exposição positiva e de outro, uma educação física que está sem prestígio ou sem significado na escola.

A educação física no Brasil surge ligada intimamente à formação e educação corporal disciplinadora, com objetivos dos mais variados: militares, de saúde, estéticos, esportivos de alto rendimento ou não, recreativos, servindo, muitas vezes, a mecanismos de alienação ou propósitos políticos, valendo-se da prática ou de eventos esportivos para desviar a atenção das tensões políticas e das lutas ideológicas ${ }^{3}$. Exemplos desses mecanismos encontram-se no jovem do final da década de 60, que o governo militar buscava para formação de um exército forte para desmobilizar correntes opositoras ao regime que 
vigorava, como também no futebol, personificado na seleção brasileira, marcava o tom vitorioso de um governo autoritário e ditatorial.

A Lei de Diretrizes e Bases da Educação Nacional (LBD) 9.394 $4^{4}$, trouxe alguns avanços para a área da educação física. Inseriu-a como disciplina obrigatória nas grades curriculares das escolas brasileiras, reconhecendo-a como componente curricular e também como área de estudo relevante na formação global dos indivíduos.

Considerando as mudanças ocorridas em relação à educação física na escola, este artigo tem por objetivo apresentar resultados de pesquisa que investigou como as mudanças ocorridas na área da educação física vêm marcando a concepção do professor e a sua prática pedagógica. Para isso, apresentamos um panorama histórico destacando as principais mudanças na área, bem como uma breve reflexão sobre a formação inicial oferecida nos cursos de educação física. Optamos por realizar um estudo ouvindo quatro docentes de educação física, atuantes no ensino público na região de Jundiaí, apresentando o que pensam sobre a área e como são afetados pelas contradições existentes neste campo de atuação.

\section{Educação Física caminhos e descaminhos}

HARDMAN $^{5}$ evidencia a forte participação da educação física nos currículos desde a antiguidade. Preparava-se o indivíduo para os desafios da vida e para a saúde, como perspectivas de uma melhor qualidade de vida social, política, no campo militar e de controle sócio-comportamental, objetivando a manutenção da autoridade e poder, servindo a interesses ideológicos desde então.

No Brasil, a importância da atividade física para a formação plena do homem foi defendida há muito tempo. O escritor Rui Barbosa, é um exemplo, que por meio de pareceres, contribuiu para reformas do ensino e para maior visibilidade da área. Segundo MARINHO ${ }^{6}$ fazendo uma alusão ao referido escritor, ressaltou que sua influência favoreceu "[...] para que, em nosso país se criasse uma mentalidade favorável à prática das atividades físicas quer sob a forma de ginástica, quer sob a de desporto ou exercício militar" (p.19-20).

Em contrapartida, os esforços para valorização da área encontravam barreiras na própria configuração dos currículos dos cursos de educação física. DA$\mathrm{MATTA}^{7}$ alerta que para muitos não seria necessário incluir em tais currículos disciplinas como Filosofia, Sociologia, Antropologia, reforçando, no professor de educação física, o estereótipo de instrutor ou educador do físico. Para CAPARroz ${ }^{8}$,

parece haver a necessidade de politizar o debate acadêmico, colocando assim a educação física em "harmonia com o momento atual". Assim, emerge uma forte crítica ao "descompromisso político" de que se impregnara a área ao longo de décadas (p.21).

Além da forte influência militar na história da educação física no Brasil, outra influência observada foi a da classe médica, que se colocava como capaz de redefinir padrões físicos, morais e intelectuais. Para isso serviu-se da educação física, buscando educar o físico e obter saúde corporal. Sob influência da área médica, mais precisamente da linha médica higienista, a educação física juntamente com um programa de educação sexual buscaria a eugenização do povo, procurando "transformar homens e mulheres em reprodutores e guardiōes de proles e raças puras" (p.44).

Segundo DAOLIO ${ }^{10}$,

o que se pretendia era a eugenia da raça, uma melhoria do padrão orgânico de todo o povo. Daí a preocupação com a mulher, a fim de que ela pudesse gerar filhos saudáveis e robustos. Fica evidente também a influência dos militares neste projeto eugênico, já que a segurança nacional deveria estar nas mãos de homens fortes e capazes (p.28).

Buscava-se criar uma sociedade robusta, harmoniosa e saudável em detrimento de uma maioria marginalizada e discriminada, segundo os olhares das elites dominantes, que eram as responsáveis por pensar a educação da época.

A partir da LDB/96, o Referencial Curricular Nacional para Educação Infantil - RCNEI ${ }^{11}$ e os Parâmetros Curriculares Nacionais - $\mathrm{PCN}^{12-13}$ propõem uma reorganização para a educação física, no que se refere ao currículo, trazendo o movimento como um aspecto central. Como componente curricular da Educação Básica, a educação física começa a ser pensada de forma integrada, valorizando o corpo e a mente dos alunos. Segundo afirma FreIRE e SCAGLIA ${ }^{14}$, "a escola não pode se ater somente à cabeça da criança, mas ao corpo inteiro" (p.7). E ainda, é "possível lançar mão das atividades corporais para educar" ${ }^{\prime 4}$ (p.8). A educação física, dentre tantos objetivos a serem alcançados, deve buscar o 
desenvolvimento de todas as dimensões intelectuais, sensoriais, afetivas, gestuais. Do contrário estará ficando aquém de suas possibilidades, empobrecendo o ensinamento e, por conseguinte a aprendizagem, perdendo a oportunidade de promover, como afirma MEdinA 15 "vidas mais cheias de vidas" (p.63).

FrEIRE $^{16}$ alerta que a educação física vem deixando de ser exclusivamente prática, trazendo para as aulas o desafio de pensar e debater assuntos do cotidiano que estejam direta ou indiretamente relacionados às práticas desportivas. Nesse sentido, SOAREs ${ }^{17}$ (p.173), reforça a ideia de que a educação física deve se desvincular dos rótulos tecnicistas indo além do saber fazer, possibilitando ao indivíduo saber pensar o que fazer, demonstrando assim que a área tem o que ensinar.

Freire e SCAGLiA ${ }^{14}$ afirmam que a quadra é sim uma sala de aula e apresenta maiores oportunidades e ferramentas de aprendizagem, rompendo com a ideia de que só se aprende confinado em pequenos espaços, em carteiras e no silêncio de uma sala de aula. A educação física tem possibilidades de desenvolver capacidades importantes além das físico-motoras, como por exemplo, a consciência coletiva e o conviver em grupo. Os jogos são exemplos claros de reprodução na quadra e o que está por vir fora dela, no que se refere ao respeito e às formas de se relacionar.

A educação física, ao longo da história tem sido uma disciplina que no interior da escola se responsabiliza pela sistematização de um conteúdo específico, tematizando saberes relacionados às práticas corporais, mais diretamente associadas às manifestações ligadas às aptidóes físicas como jogos, esporte, ginástica e luta ${ }^{18}$. Vale lembrar que perdeu força a ideia de dualidade entre corpo e mente, em que se cuidava, prioritariamente, do primeiro. A educação física nas escolas não pode estar a serviço do esporte de rendimento, em busca de selecionar os melhores em detrimento dos menos habilidosos, provocando a exclusão. Esse papel ficaria aos clubes que têm como foco principal o sucesso desportivo. Não deve também se ater somente a projetos mantenedores da saúde física e mental dos alunos, embora isso possa ser uma consequência do trabalho desenvolvido. Enfim, a educação física deve se livrar de velhos dogmas e assumir o seu papel diante do ambiente escolar, protagonizando o processo educativo e não mais como coadjuvante. Como aponta CASTELlani FilHo ${ }^{19} \mathrm{em}$ relação ao que espera da área,

a educação física tinha que romper a sua relação paradigmática com a aptidão física e tinha que se aproximar de uma outra relação paradigmática de natureza histórico-social. Então tinha que chamar para ela elementos presentes nas Ciências Humanas, nas Ciências Sociais, portanto na Sociologia, na Antropologia, na História, na Filosofia, e a partir daí orientar o processo de sua inserção na educação brasileira (p.188).

Historicamente, a formação inicial nos cursos de educação física contemplava disciplinas voltadas para a técnica de seus alunos, buscando uma excelência física e não intelectual. Segundo OLIVEIRA ${ }^{3}$, no início do século XX "a educação física compreende o conjunto dos exercícios cuja prática racional e metódica é suscetível de fazer o homem atingir o mais alto grau de aperfeiçoamento físico, compatível com a sua natureza” (p.58).

Tal afirmação demonstra porque, até o início da década de 80, a perspectiva acrítica dominava o cenário da educação física e a tônica era estudar o movimento humano, segundo abordagens desenvolvimentistas, psicomotricistas, recreacionistas e voltadas para a saúde. A partir de meados da década de 80 e início da década de 90, ganha espaço uma perspectiva crítica, na qual o indivíduo seria levado a pensar e dar sentido ao movimento realizado, daí o enfoque ao estudo do homem em movimento, com abordagens construtivistas, críticas e reflexivas.

Nos últimos anos tem-se levantado um questionamento em torno do papel da educação física dentro da escola, diante de uma perspectiva crítica que se contrapóe à tradicional, essencialmente técnica, que valoriza os desportos em detrimento da formação global. Já se percebe uma intencionalidade de mudança na educação física escolar. Mas para que a área se posicione como produtora de conhecimento, dois pontos devem ser observados: "não pode ser dogmática acreditando que tudo pode, nem cética, levando a educação física à imobilidade" 20 (p.110). BARBO$\mathrm{SA}^{20}$ ainda destaca a necessidade do diálogo entre as diversas áreas, apontando o isolamento como uma atitude contrária às pretensões da educação física.

Nesse sentido, as discussóes no âmbito da formação inicial vêm problematizando os conteúdos que devem ser priorizados, as diferentes formas de abordagens e as áreas de conhecimentos que lhe são afins. O estudo do movimento, por exemplo, pode ser pautado por técnicas sofisticadas, que buscam a perfeição, ou assumido numa perspectiva histórica e cultural, marcando de maneiras diferentes as práticas pedagógicas. Segundo CASTELLANi FILHO ${ }^{19}$, ao se defender uma perspectiva histórica e cultural é fundamental para a

prática pedagógica da educação física o desenvolvimento da noção de historicidade da cultura corporal. É preciso que o aluno entenda que o 
homem não nasceu pulando, saltando, arremessando, balançando, jogando etc. Todas as atividades corporais foram construídas em determinadas épocas históricas, como respostas a determinados estímulos, desafios ou necessidades humanas (p.40).

Desta forma, apresentamos na sequência uma breve reflexão sobre a configuração dos cursos de educação física, buscando discutir o caráter da formação docente.

\section{Educação Física: formando seus docentes}

A aproximação da educação física com a área biológica se constituiu historicamente, como já apontado. Segundo LovisOLO ${ }^{21}$, pelas características da área o discurso biomédico sempre esteve presente, ao evidenciar a prevenção de doenças e qualidade de vida, retardamento do envelhecimento ou dos desgastes neurológicos e/ou psicológicos, atribuindo à área um poder restaurador e de recuperação dos corpos.

Nessa mesma direção, DAOLIO ${ }^{18}$ destaca que depois do predomínio das ciências biológicas nas explicações sobre o corpo, a atividade física e o esporte por parte da educação física, essa tarefa hoje parece estar dividida com os conhecimentos provindos de outras áreas, tais como a antropologia social, a sociologia, a história, a ciência política e outras. Os currículos dos cursos de graduação em educação física somente há poucos anos vêm incluindo disciplinas próprias das ciências humanas, e isso parece estar sendo útil para a ampliação da discussão cultural da área (p.1).

Destacamos que tais transformações se constituem no caminho a ser trilhado pela área e seus docentes. Não queremos com isso, colocar-nos contrários à formação técnica e nem minimizar a sua relevância; mas salientar a importância da formação humanística e pedagógica para o futuro educador, contribuindo em sua prática pedagógica visando ao desenvolvimento integral de seus alunos. Como nos lembra MEdinA ${ }^{15}$, a educação física precisa pensar e repensar as suas bases filosóficas, pois carece de uma consciência filosófica, sociológica e antropológica.

Percebemos que há uma intensa discussão quanto à organização/distribuição dos conteúdos da educação física entre o que é específico e o que é geral, no que se refere aos fundamentos. Assumir uma posição requer, antes de tudo, despir-se de alguns conceitos pré-concebidos, ou mesmo mitos, sobre a ideal formação do profissional de educação física.

Segundo DAOlio ${ }^{10}$, "o próprio nome 'educação física' remete à sua compreensão para o âmbito cultural, já que supõe uma educação ou uma influência, ou uma intervenção social sobre o físico, tido como o componente natural dos homens" (p.55).

Educação física é educação, portanto, é no arcabouço desta que se deve buscar aporte teórico. Os conhecimentos humanos e sociais devem estar articulados com as áreas técnicas e voltados para o objeto de estudo da educação física, a fim de contribuir efetivamente na preparação de um docente qualificado para o exercício da profissão.

A licenciatura em educação física visa proporcionar maior conhecimento sobre Educação em geral, teoria e prática da educação física nos diferentes níveis de ensino. Cabe aqui ressaltar que teoria e prática devem estar intimamente convergentes, pois açôes práticas possibilitam alterações no que está posto. No entanto, uma teoria deve lhe dar suporte e sustentação, pois caso contrário seria apenas uma imitação, sem sentido e sem reflexão consciente e transformadora ${ }^{15}$.

Nesse sentido, o currículo se torna então um dos fatores mais importantes na formação de qualquer estudante ou profissional e precisa ser construído com base em sólido referencial teórico, marcado por uma concepção histórica, política, econômica e social, que incida diretamente, no tipo de profissional que se deseja formar. Para MARTINS ${ }^{22}$, o currículo é um espaço político e de relaçóes de poder, que reflete concepçóes e modelos do contexto da atualidade em que vivemos. GOODSOn citado por GóEs e $\mathrm{MENDES}^{23}$ sinaliza que as relações de poder também se manifestam nos "embates existentes no processo de designação da hierarquia das matérias, dentro do currículo, [que] estão relacionadas à luta por mais status, recursos e território" (p.3).

Dessa forma, o currículo tem papel fundamental nas definições do caminho a ser percorrido e pode gerar práticas pedagógicas baseadas em concepções de diferentes naturezas. Oliveira e RANZI ${ }^{24}$ alertam que a organização do currículo pode dar origem a uma atuação "não sistemática, com um suporte de conhecimentos tecnicamente sofrível, e sem muito compromisso com a formação dos alunos propriamente dita" (p.174). Observam-se algumas matrizes curriculares que reforçam um estereótipo profissional prático, o qual trabalha de modo improvisado e com suporte teórico restrito, que se agrava diante de preferências pessoais em relação ao conteúdo disciplinar apresentado aos alunos ${ }^{24}$.

A relação teoria e prática torna-se questão relevante de discussão no currículo e na formação docente. A dualidade entre esses dois aspectos vem gerando um conflito de natureza filosófica e de identidade, 
quanto à clareza de que profissional se deseja formar: o técnico ou o educador. Diante disso, o ponto primordial para as mudanças passa, obrigatoriamente, pela matriz curricular das Instituições Superiores de Ensino que formam os futuros docentes.

Quando se discute matriz curricular para o curso de educação física, até alguns anos atrás, o que se observava era uma proposta focada nas disciplinas relacionadas à área biológica como anatomia, psicologia, fisiologia ou áreas técnicas desportivas. Em alguns casos, disciplinas como estatística, administração de eventos, informática e idiomas como inglês ou espanhol constavam na matriz curricular. Os cursos de graduação formavam profissionais para atuarem nas diversas áreas abrangidas pela educação física, dentro ou fora da escola.

Entretanto, uma reforma nos cursos de educação física, em 1987 trouxe uma organização que atendia a necessidade de formação profissional especificamente para escola e outra para as demais funções atribuídas à área, fora da escola.

Diante disso, começou a se configurar uma intenção em modificar o formato dos cursos de educação física, pensando na formação dos profissionais que atuariam fora da escola - os bacharéis - e os que atuariam nas escolas - os licenciados. A formação dos primeiros contava com disciplinas voltadas para áreas como a desportiva, da saúde ou mesmo para pesquisa e a formação docente dava ênfase às disciplinas pedagógicas e específicas para o ambiente escolar.

Os cursos de licenciatura em educação física ao longo dos anos vêm sofrendo com a falta de uma identidade profissional e também a ausência de um objeto de estudo claro para área. Por sinal, esta é uma das características da educação física, decorrente da diversidade de abordagens e consequente abrangência de seu campo de estudo, com suas múltiplas identidades ${ }^{21}$.

LOVISOLO $^{21}$ compara os currículos das instituições superiores de educação física a um mosaico ou uma colcha de retalhos. Obstáculos como desarticulação entre teoria e prática, cisão entre formação pedagógica e formação específica, acrescido de uma tendência ao encurtamento na duração dos cursos superiores, apesar de não ser exclusividade dos cursos de Educação Física, afetam a qualidade da formação.

Para entender esse cenário, que envolve as diretrizes curriculares, coletamos informaçōes em matrizes curriculares de algumas Universidades, levando em conta a sua composição e objetivando, com isso, enxergar o docente que será formado pelas mesmas. Tivemos a preocupação, em nossa análise, de levar em consideração, nas matrizes curriculares analisadas, em primeiro lugar a formação do professor de educação física voltado à atuação na educação básica. Como segunda preocupação, levamos em conta a construção do saber docente diante das matrizes selecionadas; verificando se as mesmas estariam em conformidade com as interfaces na dimensão educacional e com os saberes das ciências humanas que, ao nosso entender, são decisivos na formação do futuro docente. As matrizes foram analisadas observando a articulação entre as disciplinas acadêmicas, no que se refere às questôes da escola, da pedagogia e da própria educação física, identificando, portanto, quanto do conjunto todo do curso se destina às disciplinas relacionadas a conteúdos específicos e quanto se destina às disciplinas para formação de professores.

Foram escolhidas cinco universidades obedecendo a um critério básico, todas deveriam ser universidades públicas. As quatro primeiras foram: USP (Universidade de São Paulo), UNICAMP (Universidade Estadual de Campinas), UNESP (Universidade Estadual Paulista), UFSCar (Universidade Federal de São Carlos), as quais se localizam no estado de São Paulo, e são consideradas referências educacionais em nosso país. A quinta universidade foi a UFV (Universidade Federal de Viçosa), também pública, mas localizada fora do estado; cuja escolha se deu em razão do ótimo desempenho do curso no último ENADE em 2008, no qual obteve a nota mais alta (5), deixando o curso de educação física entre os cinco melhores desta universidade.

Analisando a matriz curricular da Universidade de São Paulo (USP), observamos que no curso de licenciatura as disciplinas são distribuídas em oito semestres, totalizando uma carga horária de 3.810 horas, sendo 400 horas de estágio. Ao observarmos a organização das disciplinas, em seus respectivos semestres, pudemos perceber com clareza que do $1^{\circ}$ ao $4^{\circ}$ semestre dá-se uma ênfase maior às disciplinas biológicas, tendo um equilíbrio entre estas e as disciplinas esportivas e uma menor frequência das disciplinas humanas. Do $5^{\circ}$ ao $8^{\circ}$ semestre, existe uma inversão marcante. As disciplinas biológicas e esportivas praticamente desaparecem da grade eletiva, apresentando-se apenas no elenco de disciplinas optativas, evidenciando, portanto, nesse momento do curso, as disciplinas da área das Ciências Humanas. Tal aspecto nos sugere que estando o aluno em um maior nível de desenvolvimento, a USP passa a fortalecer o curso no âmbito da educação, pois primeiramente o curso dá ênfase e amplia o campo de conhecimento da área, investindo, na sequência, no trabalho de formação docente propriamente dito. 
A matriz curricular da Universidade Estadual de Campinas (UNICAMP) apresenta também um curso de licenciatura dividido em oito semestres, com uma carga horária de 3.225 horas. Observamos que essa carga horária está dividida em horas de prática como componente curricular, de estágio supervisionado, de conteúdos curriculares de natureza científico-cultural e outras atividades acadêmico-científico-culturais. Outra particularidade se dá ao fato de que, tanto a licenciatura como o bacharelado têm um núcleo comum chamado de central, que equivale à aproximadamente $70 \%$ do curso, deixando os outros $30 \%$ para um núcleo denominado específico para uma ou para a outra modalidade. Ressaltamos que fazem parte do núcleo central da habilitação em licenciatura, as disciplinas voltadas ao universo escolar, tal como os estágios; estando as disciplinas de cunho esportivo, em sua quase totalidade, no núcleo central, mas como disciplinas optativas e com créditos reduzidos. $\mathrm{Ou}$ seja, nesse curso a ênfase maior não está na formação do técnico e sim na formação do docente. Quanto ao núcleo central, existe um equilíbrio entre disciplinas biológicas, humanas e esportivas, pois ele atende também o curso de bacharelado.

A matriz curricular da Universidade Estadual Paulista (UNESP) apresenta um formato parecido com o da UNICAMP. Também oferece um curso de licenciatura dividido em oito semestres, com disciplinas comuns ao curso de licenciatura e de bacharelado, mas oferece também disciplinas específicas para a licenciatura, de cunho pedagógico e humanístico. A carga horária é de 2.910 horas, apresentando também semelhança com a USP ao priorizar, nos primeiros semestres, disciplinas biológicas e esportivas, deixando para os quatro últimos semestres as disciplinas voltadas para a formação docente. A matriz curricular contempla disciplinas teóricas específicas na metade final do curso. Inferimos que nessa etapa, o aluno já se encontra com certa bagagem acadêmica, podendo melhor realizar suas escolhas. Desta forma, é na metade final do curso que se encontram as disciplinas da área pedagógica.

A matriz curricular da Universidade Federal de São Carlos apresenta um curso com duração de oito semestres, com carga horária de 3.240 horas. Nos quatro primeiros semestres existe um equilíbrio entre as disciplinas biológicas e esportivas, com uma pequena ênfase nas disciplinas humanas e afins. A partir do $5^{\circ}$ semestre, passa a não ter a presença de disciplinas da área biológica, com queda nas disciplinas esportivas e com um grande aporte de disciplinas humanas, assemelhando-se assim às demais matrizes até aqui observadas. Entendemos, portanto, que essa seja uma tendência ao menos das universidades analisadas: investir nos conhecimentos específicos da educação física inicialmente e, progressivamente, inserir o discente no ambiente educacional, dando ênfase às disciplinas que acreditamos, formarão o docente crítico e autônomo.

Por fim, a Universidade Federal de Viçosa apresenta uma matriz curricular muito próxima às demais, pois enfatiza as disciplinas humanas apenas a partir do $5^{\circ}$ semestre, deixando as disciplinas biológicas e esportivas ganhar mais espaço nos primeiros semestres. O curso de licenciatura conta com 3.200 horas. $\mathrm{O}$ que chamou a atenção foi que tanto o curso de bacharelado como a licenciatura têm a mesma carga horária; porém a divisão se faz de maneira diferente entre eles, principalmente no que se refere às disciplinas optativas. No curso de licenciatura a carga horária para as disciplinas optativas é menor, tornando-o mais fechado e enxuto. $\mathrm{O}$ aluno tem opçôes restritas a algumas disciplinas biológicas, humanas e esportivas, tendo cumprido, nas disciplinas obrigatórias, muito do que realmente lhe será necessário, inclusive todos os estágios supervisionados e o TCC. Há opções, mas elas não são muito abrangentes. Desta forma, inferimos que os riscos de dispersão ou de escolhas desconexas com a realidade educacional são menores.

Diante dessa rápida análise das matrizes citadas, percebemos que as universidades têm buscado se adequar às novas realidades e necessidades, principalmente no que diz respeito à dimensão pedagógica voltada agora, exclusivamente, para o ambiente escolar - da Educação Infantil até o Ensino Médio. As Universidades observadas têm em suas matrizes um equilíbrio entre as disciplinas biológicas e desportivas, dando ênfase às disciplinas humanas e pedagógicas. Com isso esperamos que "o produto dessas escolas não sejam atletas, mas professores"3 (p.102).

Segundo DAOLIO ${ }^{10}$ o tipo de formação, na maioria das vezes, leva "estes profissionais à falta de embasamento teórico, falta essa que impediria a transformação de sua prática" (p.36). O que nos surpreende é que para alguns docentes o foco de suas aulas é mesmo as habilidades esportivas, afastando-se do perfil de educadores e aproximando-se do papel de técnicos ou de atletas, com uma educação física excludente e exclusivamente prática e de rendimento.

Não se pode pensar o trabalho com o movimento corporal segundo a perspectiva do aprender a aprender, promovendo com isso saberes espontâneos e, consequentemente, o enfraquecimento do papel do professor, enfatizando o fazer pelo fazer. 
Para SAVIANI ${ }^{25}$, seria o esvaziamento da docência, tornando-se um facilitador pedagógico.

Dessa forma destacamos, que segundo GÓES eMENDES ${ }^{23}$, a educação física deveria ter mais prestígio no currículo escolar, em especial, por se tratar de uma disciplina que tem a possibilidade de ser desenvolvida fora e dentro de sala; também por tratar de temas que estimulam o pensar, refletir, questionar sobre os problemas educacionais, sociais e culturais enfrentados pela sociedade, bem como, interferir com propostas inovadoras para solução de tais problemas (p.10).

\section{Método}

Trata-se de uma técnica de entrevista que possibilita a retomada das informaçóes coletadas visando ao aprofundamento e esclarecimento.

A entrevista recorrente consiste, segundo LEITE e $\mathrm{COLOMBO}^{27}$, em um processo de maior interação entre pesquisador e sujeitos na construção "do conhecimento sobre o tema de maneira partilhada e planejada" (p.128). Envolve um número reduzido de sujeitos e escolha intencional dos mesmos. Baseia-se, inicialmente, em entrevistas individuais abertas, gravadas em áudio, contando com uma questão disparadora e com pouca interferência do pesquisador. Esse primeiro momento de coleta de dados é transcrito e submetido a uma análise inicial para categorização, bem como para elaboração de um roteiro norteador do segundo momento de entrevista, em que os sujeitos são incentivados a completar/alterar/propor novos arranjos e o pesquisador pode solicitar esclarecimentos de informaçóes. Nessa segunda etapa as entrevistas são semi-estruturadas, com uma participação mais ativa do pesquisador, tendo como foco o problema da pesquisa para que não haja dispersão. Novas transcrições e análise dos dados colhidos, neste segundo momento, levam a uma nova categorização, forçando um novo encontro no qual o sujeito novamente lê toda a entrevista tendo a disposição os trechos do primeiro e do segundo momento e suas categorizaçóes, incluindo novas categorias, caso tenham surgido. No terceiro encontro, o sujeito novamente, se achar necessário, indica arranjos, complementos, faz esclarecimentos e o pesquisador pode solicitar detalhamento das informaçóes já fornecidas. Quando mais nada tiver para acrescentar, encerra-se o encontro, deixando agendado mais um e, neste caso o último, para uma revisão geral e definitiva. É importante destacar que essa dinâmica pode ocorrer de forma diferente de sujeito para sujeito, variando o número de encontros.
A área de educação física hoje deve assumir o papel que lhe é conferido por diferentes documentos (PCN, LDB etc.), quanto à sua relevância dentro da estrutura escolar, promovendo "o desenvolvimento de diferentes capacidades cognitivas, afetivas, físicas, éticas, estéticas, de inserção social e de relação interpessoal"26 (p.143).

A seguir, apresentamos os aspectos metodológicos da pesquisa, que obteve aprovação do comitê de Ética, em 27/07/2010, sob o protocolo $n^{\circ} 689 / 10$, bem como dos sujeitos que participaram da mesma.

Como parte prevista nos procedimentos, inclui-se a possibilidade de novas entrevistas, caso necessário ${ }^{27}$.

O problema de pesquisa baliza a realização das entrevistas e também a quantidade de encontros a serem feitos com cada sujeito, tendo como referência o momento em que pesquisador e sujeito acordam que se esgotaram as informaçôes a respeito da problemática da investigação. A questão disparadora, para o primeiro encontro, com cada um dos sujeitos entrevistados foi: Como se deu a sua escolha pela educação física e que significado ela tem na sua docência e na vida de seus alunos? A coleta de dados envolveu quatro professores de educação física do ensino público, com tempo de formado e de docência diferentes, vinculados à Diretoria de Ensino de Jundiaí.

Cabe ressaltar que os resultados aqui apresentados não deverão ser generalizados para outras instituições de ensino ou mesmo outros profissionais, mas poderão servir de referência para outros pesquisadores neste campo de estudo.

\section{Amostra}

A escolha dos sujeitos se deu observando alguns critérios. Além de serem professores que trabalham somente no ensino público, consideramos que era importante que tivessem significativa carga horária de aulas na mesma escola, bem como uma diferenciação no que se refere ao tempo de formado e ao tempo de atuação no magistério. Intencionalmente, foram selecionados sujeitos formados nas décadas de 70, 80, 90 e 2000. Com isso, buscamos identificar como as mudanças sofridas pela educação física ecoavam nos discursos desses professores. Vale ressaltar que, a definição por essas décadas não corresponde necessariamente, 
a marcos significativos de mudanças em relação à educação física. Fizemos a opção por esses intervalos de tempo por acreditar que a diferença entre o tempo de formação entre os sujeitos, que, consequentemente, resulta, em nosso caso, em um tempo diferente de efetivo exercício na área, pudesse nos trazer, nos discursos, concepções diferentes em relação ao olhar para a educação física.

O primeiro sujeito (S1) tinha 53 anos, é do sexo feminino e formou-se em 1977 pela Universidade de São Paulo - USP. Atua na área desde formada e, especificamente, no ensino público, desde 1993. Em 2000 concluiu curso de complementação Pedagógica em Amparo. Foram realizados quatro encontros.

O segundo sujeito (S2) tinha 27 anos, é do sexo masculino e formou-se em 2005 pela Universidade de Sorocaba - UNISO. Atua na área há oito anos e no ensino público, desde 2003, quando ainda era estudante. Concluiu três cursos de pós-graduação na área da Educação Física Escolar e Técnico Desportivo. Ao todo foram realizados três encontros.

O terceiro sujeito (S3) tinha 32 anos, é do sexo masculino e formou-se em 1999, pela Escola Superior de Educação Física de Jundiaí - ESEFJ. Atua na área desde 2000 e no ensino público, desde 2007. Concluiu cursos de pós-graduação na área da Fisiologia do Exercício. Dá extrema importância para sua contínua formação pedagógica e atualização profissional. Foram realizados com este sujeito três encontros ao todo.

O quarto sujeito (S4) tinha 47 anos, é do sexo masculino, formou-se em 1985, pela Escola Superior

\section{Resultados e discussão}

\section{Núcleo 1: Formação inicial}

Aqui identificamos, nos discursos dos quatro professores entrevistados, aspectos relacionados à escolha de cada um pela educação física, à importância da formação inicial para o exercício da docência e aos problemas identificados na própria formação de cada um deles. Nesses dizeres identificamos algumas influências da organização dos cursos de formação inicial que, até alguns anos atrás, tinha um formato de licenciatura ampliada ou plena e hoje está dividido em licenciatura e bacharelado. Este aspecto, sem dúvida, exerce influência na formação e, consequentemente, nas práticas pedagógicas.

Os dados demonstraram que S1 formada em 1977 e S3 formado em 1999 apontaram para uma de Educação Física de Jundiaí - ESEFJ. Atua na área desde 1987, inclusive no ensino público. Concluiu cursos de pós-graduação na área de Educação Física Escolar e Técnico Desportivo. Em 2005 concluiu complementação Pedagógica o que lhe proporcionou uma experiência, no ano de 2007, na gestão escolar como vice-diretor. Acredita que essa importância que tem dado a sua contínua formação pedagógica e atualização profissional o mantém motivado ainda após 24 anos de atuação na área. Três encontros foram realizados com esse sujeito.

Todos os encontros tiveram uma duração média entre 60 e 90 minutos.

\section{Análise dos dados}

Diante dos dados obtidos nos vários encontros, por meio das entrevistas recorrentes fomos identificando categorias juntamente com a anuência dos sujeitos entrevistados, que retratassem aspectos relacionados às formas como as mudanças pelas quais a educação física passou ecoam nos discursos. Assim, após a categorização realizada com cada sujeito, separadamente, durante os encontros, o processo de tratamento dos dados resultou em um trabalho, desta vez dos pesquisadores, de articulação das respectivas categorias, visando à construção de núcleos, representando indícios das mudanças ocorridas na educação física, nos discursos dos sujeitos entrevistados. Foram elaborados três núcleos: Formação Inicial; Atuação do Docente na Área; Relação Docente x Sociedade.

área cheia de facilidades e livre em relação a outras disciplinas, pelo fato de não ser "presa dentro de uma sala" (S1) e de achar "moleza o serviço do professor" (S3). Nesse sentido, levantamos os seguintes questionamentos: a educação física se reduz apenas ao brincar, entreter ou recrear? Em razão de a educação física envolver atividades realizadas, na maioria das vezes, em quadras carrega a marca de uma facilidade maior em relação às outras áreas? Ou ainda; em razão do espaço onde o ensino e a aprendizagem ocorrem, que geralmente é a quadra, a educação física é considerada como um componente curricular "livre"? Será que esse "livre" não está relacionado à liberdade de se fazer o que quiser sem que haja uma intenção e uma sistematização, conforme S3 coloca - uma "moleza"? Tais questionamentos e aspectos reforçam 
muitas vezes a desvalorização da área e do próprio docente em formação.

Por outro lado, S2, formado em 2005 evidencia a influência do período militar como positiva para se resgatar o valor do professor:

tem gente tentando mudar, mas vai demorar, é a

longo prazo. Para voltar como era, por exemplo,

na época militar, o professor de educação física era

bem valorizado, vai demorar (S2).

DAOLIO $^{10}$ afirma que, durante o governo militar, a educação física ocupava um espaço estratégico no país. Os militares tinham interesse pela área no intuito de ter uma nação preparada para guerra. Nesse sentido, ressaltamos que a inclusão da educação física nas escolas do país ocorreu em 1929 que, segundo o mesmo autor, tinha a clara intenção de disseminar a ideologia militar, o adestramento físico preparando os jovens para cumprimento de deveres, lembrando que os docentes da época ou eram militares ou formados nas escolas militares. Observamos que os docentes eram levados a acreditar que prestavam um grande serviço ao país enquanto valorizavam em demasia os esportes e menos o intelecto. Não havia na época a percepção por parte dos docentes que na verdade serviam aos interesses do poder e com isso desmobilizavam qualquer tentativa de reprovação ao modelo dominante, envolvendo principalmente os jovens. Por tudo isso, cabe questionar se os docentes eram valorizados, respeitados por consideração e compreensão ou eram temidos por servirem a um governo sabidamente repressor?

O que nos surpreende é que S2 não se formou nessa época e, mesmo assim, compartilha de opinióes assumidas por alguns como o Prof. Carlos Sanches Queirós que enaltecia a Escola de Educação Física e o modelo militar para área no passado, destacando que era dado e devido muito respeito?. Sem dúvida tratase de um período marcante para história da educação física brasileira, mas longe de ser uma unanimidade, pois para muitos esse modelo de educação física servia a uma educação "desideologizada" e "despolitizada", ${ }^{28}$ (p.119). Pontos que interferem diretamente em uma valorização da área e de seu docente.

No discurso de $S 1$ identificamos como a educação física é considerada:

tem gente tentando mudar, mas vai demorar, é a

Para a maioria dos futuros docentes a educação

física é jogar bola (S1).

CARVALHO $^{28}$ alerta para a ideia de que a educação física está apenas para os exercícios físicos e esportes, assumindo o papel de entretenimento, de recreação ou de socialização.
SouZA e $\mathrm{VAGO}^{29}$ destacam exatamente o menor prestígio da Educação Física em relação às outras áreas devido a sua ligação com aspectos corporais e motores e menos intelectuais e cognitivos. Tal aspecto foi identificado no discurso de S1:

Pois ainda hoje eu observo professores que foram fazer uma graduação em educação física por acreditar que era fácil. Que ele iria jogar na faculdade e após faria o seu aluno jogar também. Eu acho que a qualificação dos mais novos é pior (S1).

Por outro lado, a aproximação entre a educação física e a saúde, bem estar e qualidade de vida pode trazer uma marca positiva em relação à própria área, como demonstrou S4, formado em 1985:

desde quando estudava dizem que a educação física

é a profissão do futuro, tem 24 anos que dou aula

e ainda continuam dizendo que é a profissão do

futuro (S4).

Aqui, vale ainda algumas reflexões: Qual é a ideia de profissão do futuro para esse docente? E o seu compromisso como docente na construção desse futuro? Seria relacionado ao aspecto financeiro? Uma profissão que garanta um futuro tranquilo economicamente? Parece que S4 desconsidera o quanto o esporte avançou e quanto isso vem influenciando o universo da área da educação física. Por outro lado, em 24 anos de docência o quanto se colocou como protagonista na construção desse futuro? O que temos certeza é que a concretização da promessa aguardada por $\$ 4$ passa pela formação inicial, mas também pela formação continuada. Para Hargreaves ${ }^{30}$, a formação inicial é o primeiro momento de uma formação docente que irá continuar por toda vida, até porque, a formação inicial não é suficiente. Os desafios são muitos e vão além da formação inicial, como explicou $\mathrm{S}$ :

Falta não só capacitação para o uso do material como também de capacidade para atuar na área como um todo (S1).

Destacamos a importância de o docente manterse atualizado e em constante formação. Conforme nos aponta NASCIMENTO citado por MERCADO ${ }^{31}$ é fundamental.

a formação recebida por formandos já profissionalizados e com vida ativa, tendo por base adaptação contínua a mudanças dos conhecimentos, das técnicas e das convicçôes de trabalho, o melhoramento de suas qualificaçôes profissionais e a sua promoção profissional e social (p.105).

Podemos então, diante disso, reconhecer que a formação continuada pode agir positivamente na melhoria das práticas pedagógicas e com isso trazer 
maior qualidade para o ensino da educação física, como também das demais áreas.

$\mathrm{O}$ discurso de $\mathrm{S} 1$ trouxe dados que nos levaram a um docente que ainda vê a área como exclusivamente prática e desportiva, abordagem hoje ultrapassada nas universidades. Já S3, que é um docente relativamente jovem na área e, portanto recentemente formado, vivenciou, com certeza, uma formação diferente de S1. S3 é fruto de um currículo mais equilibrado entre as áreas biológicas e humanas e assume a responsabilidade de, por opção pessoal, envolver-se mais com as disciplinas da área da biologia e menos com as disciplinas da área de humanas e pedagógicas.

Os dados demonstraram que os sujeitos identificaram algumas dificuldades no seu exercício profissional e que claramente têm a ver com as opções que fizeram anteriormente. Já outros localizaram problemas e deficiências na própria formação inicial, que independe de postura ou mesmo grau de interesse. Nesse sentido, comentou S4: "minha formação não tem nada a ver com o que faço hoje."

Percebemos então que as mudanças de hoje, que passam por aspectos na área cientifica, tecnológica e de conceitos, obrigam o docente a estar em contínua atualização. AlarCÃO ${ }^{32}$ reforça a tese de que a formação de um docente nunca acaba. Como explicitou S4 o campo profissional que escolheu e para o qual foi preparado não tem mais a ver com o que ele aprendeu. Evidenciamos a questão da formação em serviço. Segundo CarRasCosA ${ }^{33}$

a formação de um professor é um processo a longo prazo, que não se finaliza com a obtenção do título de licenciado (nem mesmo quando a formação inicial tiver sido de melhor qualidade). Isso porque, entre outras razões a formação docenteé um processo complexo para o qual são necessários muitos conhecimentos e habilidades, impossíveis de serem todos adquiridos num curto espaço de tempo que dura a Formação Inicial (p.10-1).

A formação inicial de $S 4$ foi tecnicista e fez parte de um momento em que na educação física a abordagem desenvolvimentista se mostrava hegemônica nos cursos de graduação. Desta forma, o aspecto motor era valorizado e enaltecido por meio dos esportes e jogos sempre com características motoras e psicomotoras. Sua graduação se deu na década dos anos 80 e segundo ele eram passados ensinamentos técnicos e práticos, para que o trabalho fosse realizado exclusivamente em quadra - "A teoria era no máximo as regras dos esportes e alguma coisa na área biológica (S4). Por isso, ele ainda nos trouxe outras dificuldades em decorrência de sua formação inicial e que se apresentou como um dos obstáculos à prática docente: "tive muita dificuldade quando me vi dentro da sala de aula" (S4). A marca desenvolvimentista de um período tecnicista tinha como referência que o "movimento é o objeto de estudo e aplicação da educação física"18 (p.15). Observamos a forte influência do aspecto motor e da prática pela prática.

Foi difícil para mim e acho que deve ser para outros

também, somos fruto de nossa formação. [...] Nossa

formação era tecnicista, generalista. Saíamos técnicos de modalidades, para ensiná-los na prática, a prática (\$4) .

Os discursos dos quatro professores entrevistados indicaram os desafios e obstáculos a serem transpostos no exercício da profissão, entre eles a busca de formação para além da inicial e ainda, para além de práticas corporais de movimentos.

Em contrapartida, não se pode negar que a maneira como os cursos de formação inicial de educação física foram e são organizados marcam os modos de pensar e agir dos seus egressos. Sem dúvida, tais modos podem sofrer transformaçōes, ao longo da trajetória profissional, por influência de novos saberes produzidos na prática e da prática ${ }^{34}$.

No que se refere ao formato da graduação em educação física cursada pelos professores entrevistados, temos o seguinte: S1 e S4 formaram-se em um curso de duração de três anos com um perfil técnico, esportivo e promotor de saúde através das aptidões físicas. Como já apresentado, vivenciaram mais a abordagem desenvolvimentista da educação física, com uma influência esportiva forte. Já S2 e S3, por concluírem o curso mais recentemente, tiveram uma formação com duração de quatro anos e com uma matriz curricular equilibrada entre as áreas biológicas, esportivas e humanas, o que nos leva a apostar em um docente diferente dos anteriores quanto à sua formação e adaptação às novas características da área. Vivenciaram uma época em que, segundo $\mathrm{KuNZ}^{35}$, a educação física recebeu influências de abordagens críticas, trazendo diferenças na forma de compreender e organizar a prática pedagógica. Inicia-se um contraponto à hegemonia biológica e tecnicista. Mesmo assim, S3 demonstrou se ressentir da falta de mais elementos durante a graduação, a respeito das possibilidades e formas de atuação do profissional, nos diferentes campos de trabalho:

não creio que o mais importante seja a separação da licenciatura do bacharelado, mas o devido esclarecimento no ensino regular das diferenças, objetivos, campos de atuação e principalmente, de intervenção social que cada um vai ter (S3).

$\mathrm{KuNZ}^{35}$ propõe para os cursos de formação inicial e continuada uma abordagem que vá além do movimento 
corporal e busque aproximaçóes com aspectos socioeducacionais, socioeconômicos e políticos.

Portanto, o que se evidenciou neste núcleo foi a confirmação da ideia de lazer, de facilidade que acompanham a educação física. Da mesma forma destacou-se uma fragilidade em relação às especificidades dos conhecimentos e as possibilidades de atuação profissional.

\section{Núcleo 2: Atuação do docente na área}

Aqui identificamos nos discursos dos quatro professores aspectos relacionados à forma com que eles organizavam suas práticas, como as consideravam, passando pelas condições de trabalho oferecidas a cada um deles. $S 1$ indicou que se ressente da falta de comprometimento por parte dos docentes, como também do corpo gestor:

cada um chega lá e faz o que quer. E quando ele não quer, ele vai e não faz. Apesar de nós termos um currículo entre aspas de educação física, para a escola se ele for cumprido ou não, não faz diferença (S1).

Certamente que a questão da falta de compromisso com a profissão não é um problema exclusivo da área da educação física, mas inferimos que por ser vista como uma atividade de quadra, que trabalha com jogos, isso aumenta a probabilidade da falta de comprometimento com o processo educacional e com o projeto pedagógico da escola.

A falta de compromisso do docente leva à falta de compromisso dos alunos, que, muitas vezes percebem as aulas de educação física como diversão e podem trazer a falsa ideia de realização de um bom trabalho, destacou S3:

os alunos são muito mais felizes com aulas livres,

onde eles possam jogar o que eles querem jogar.

Deixá-los brincar como eles querem pode ser um

jeito de me enganar quanto à aula ter sido boa (S3).

Para a educação física não é positivo ancorar a sua prática apenas no prazer do aluno ou do docente, o aluno vai para a escola para aprender algo. Outro desafio é fazer com que nas aulas de educação física se articule aprendizagem e prazer, pois se corre o risco de o professor se tornar desnecessário no ambiente educacional, bastando apenas espaço e material disponível para os alunos jogarem.

Houve um processo, no início dos anos 90, envolvendo discussões na esfera das Diretorias de Ensino do estado de São Paulo, com a participação de docentes de educação física, a respeito da necessidade de organização curricular, definindo conteúdos para área. A princípio, o que se revelava era um grande desejo de se configurar a educação física como as demais disciplinas. Mas, será que para se garantir um conteúdo específico para a área o caminho é um material didático que seja um guia para toda a rede do Estado de São Paulo?

Nesta questão, os dados coletados trouxeram comentários a respeito dos Cadernos do Professor e do Aluno que foram distribuídos no Ensino Fundamental anos finais e Ensino Médio nas escolas públicas estaduais de São Paulo e fazem parte do Currículo da Secretaria de Educação. Estes Cadernos trazem propostas de uma sistematização de conteúdos definidos para cada área do conhecimento. S3 e S4 comentaram sobre este material:

pode ser um norte, mas se é um norte não pode ser obrigatório (S3).

não pode fugir da essência da área que são as atividades práticas (S4).

Observamos que em um primeiro momento, parece que S3 expressou certa concordância com o material e seu propósito auxiliador, mostrando algum otimismo em relação ao seu objetivo e à sua função no contexto escolar. Mas na segunda parte da fala deixou transparecer uma posição de contrariedade quanto à obrigatoriedade do uso deste material, deixando no ar, a ideia de que ter uma referência quanto aos conteúdos e formas de trabalhar é bemvinda, desde que não engesse a prática pedagógica.

Já S4 salientou que há um risco na sua visão - "para que o aluno tenha acesso a um conteúdo teórico específico, a disciplina pode perder a sua 'essência', ou seja, seu caráter prático" (S4). Desta forma, não defende a área como exclusivamente prática, mas apenas teme por exageros, pois o material propóe atividades para serem realizadas na classe, mudando o ambiente característico da educação física - a quadra. Salientamos que pode se constituir em um desafio equilibrar as atividades do caderno do aluno em classe ou extra classe e, as atividades em quadra ou outro espaço externo.

Ainda em relação aos Cadernos do Professor e do Aluno outras questões foram apontadas pelos professores entrevistados:

Os que estão atrapalhando entre aspas, [se referindo aos professores sem compromisso] estão se dando um pouco melhor em virtude de terem um caderno de atividade pronto e poder segui-lo sem a busca por nada (S1).

Continua tudo do mesmo jeito, nada tem mudado. Não acontecem na prática; [mudanças, abordagens trabalhadas nas faculdades] (S2). 
Bom para o professor que está perdido, mas não vai ser útil para aquele que já tem claro exatamente os aspectos que ele quer trabalhar (S3).

Não ajudarão em nada [os Cadernos] (S4).

$\mathrm{Na}$ opinião de S1 e S3 o material tem servido de apoio pelo menos a um grupo de docentes, que $S 1$ qualifica como "atrapalhando". Ou seja, docentes que estão em dificuldades e acabam por contribuir com a imagem distorcida da área. S3 usa para esse modelo de docente o termo "perdido", aquele que precisa de ajuda, pois pode incorrer em erros ou se acomodar. O que difere na fala destes sujeitos é que para $S 1$ este material não servirá de apoio no sentido de auxílio, contribuindo para a atuação docente e, consequentemente valorizando a área, mas sim como uma bengala em que o docente irá se apoiar. Já S3 acredita no auxílio, mas o considera inútil para aquele docente que sabe exatamente o que deve fazer, o papel que deve assumir perante a área, sua prática e diante do projeto pedagógico da escola.

A elaboração e distribuição de material didático resultante de políticas educacionais que definem concepções diversas em relação às áreas de conhecimento têm contado com muitas resistências no interior das escolas. A questão das diferentes abordagens teóricas torna-se um campo de tensões e de confusões, que transitam entre purismos teóricos e mal entendidos. Assim, S3 explicita:

A minha grande crítica [...] é que não dá para você misturar teorias, pois uma vai falar mal da outra em algum aspecto. A minha grande briga com eles é que a gente não tem que ter uma só teoria. Quando seguimos por um caminho privilegiamos um aspecto e o ser humano não é feito de um aspecto, ele tem vários $[. .].(\mathrm{S} 3)$.

Para S3 não só a participação, ou no caso a falta dela por parte dos docentes, interfere na aplicação e aceitação em relação ao material, mas principalmente, por haver uma "guerra de vaidades" entre os acadêmicos. Disputam para impor essa ou aquela abordagem, esse ou aquele modelo, quando na verdade deviam juntar-se e olhar para área. $\mathrm{O}$ tom conciliador não significa dizer que está tudo certo, mas demonstraria bom senso, por parte daqueles que pensam e discutem a área dentro das universidades como uma ciência, como um campo de conhecimento específico. Para S3 o que atrapalha é que "uns poucos decidem o que muitos irão fazer" e tomam isso como uma "verdade absoluta" como única opção a ser seguida. Em seu ponto de vista isso tem atrapalhado mais do que beneficiado a área.

Por outro lado, o que a Secretaria de Educação do
Estado de São Paulo (SEE/SP) buscava com a implantação desse material que se constitui um currículo escolar para educação física era a superação de uma prática descontextualizada, na direção de uma apropriação crítica da cultura de movimento, a sistematização proposta nos Cadernos do Professor e do Aluno, como recurso didático, afigura-se como ferramenta valiosa para a contextualização [...] pretendida pela proposta ${ }^{2}$ (p.186).

Percebemos além de uma intenção, uma ação concreta que vai ao encontro de um grande anseio da área que é a sistematização dos conteúdos próprios da educação física. Outro aspecto evidenciado no material da SEE/SP se refere aos espaços onde o trabalho se desenvolve.

A quadra é o tradicional espaço da aula de educação física, mas algumas situações de aprendizagem [...] podem ser desenvolvidas no espaço da sala de aula, no pátio externo, na biblioteca, na sala de informática ou na sala de vídeo, ou em espaços na comunidade local, desde que compatíveis com as atividades programadas ${ }^{2}$ (p.185-6).

Não estamos apostando em uma educação física sem prática, mas não exclusivamente prática que impeça a realização de um trabalho consciente e de reflexão na área.

Observamos, portanto que o material didático trouxe mudanças que vêm interferindo na organização da prática. Enquanto alguns acreditam em um avanço, um norte ou mesmo uma tentativa de sistematização, percebemos que ainda isso não ocorre de maneira uniforme. Falta legitimidade para os Cadernos e por isso não há muito compromisso em colocá-los em prática no cotidiano escolar, mesmo como material de apoio. Já para outros docentes, esse material aparece como único elemento de aprendizado para área. Percebemos que há, muitas vezes, a utilização de maneira equivocada como um instrumento punitivo caminhando no sentido inverso da proposta. Este material tem no fundo o objetivo de minimizar os desafios e deixar para trás um passado descontextualizado, principalmente quanto à seleção de conteúdos para área. Nesse sentido os Parâmetros Curriculares Nacionais de Educação Física destacam que:

Quanto à seleção de conteúdos para as aulas de educação física, sugere que se considere a sua relevância social, sua contemporaneidade e sua adequação às características sociocognitivas dos alunos. Em relação à organização do currículo, ressalta que é preciso fazer o aluno confrontar os conhecimentos do senso comum com o conhecimento científico, para ampliar o seu acervo. Além disso, sugere que 
os conteúdos selecionados para as aulas de educação física devem propiciar uma melhor leitura da realidade pelos alunos e possibilitar assim, sua inserção transformadora nessa realidade ${ }^{12}$ (p.25-6).

Para alguns docentes os desafios na escola passam por aspectos menos metodológicos e didáticos e mais por aspectos estruturais e de reorganização, como percebemos particularmente na fala de S4. Este pontuou decisivamente como entrave para área, em relação às condiçõoes de trabalho disponíveis, o fato das aulas de educação física terem sido deslocadas para o turno, ou seja, para o mesmo período em que as outras aulas acontecem, estando agora junto aos demais componentes curriculares da escola:

Fora do período o interesse ainda era maior [...] para se trabalhar era melhor (S4).

Até meados da década de 90 as aulas de educação física aconteciam no contra turno, isto é no período contrário às demais aulas do dia. Por exemplo, os alunos que estudavam pela manhã, frequentavam as aulas de educação física no período da tarde e os alunos que estudavam no período da tarde faziam o inverso. Mas ainda na mesma década, mais precisamente a partir da aprovação da Lei de Diretrizes e Bases da Educação Nacional (Lei no. 9394/96), as aulas de educação física foram deslocadas para o próprio turno, principalmente em instituições públicas de ensino, juntamente com as demais disciplinas. Isso ao mesmo tempo em que gerou pontos positivos, como menor deslocamento dos alunos que indo embora da escola deveriam voltar no período inverso para aula, o que geraria custo com transporte, que muitas vezes a família não tinha condições de arcar e muito menos o poder público, gerou também dificuldade como a evasão. Outro ponto positivo defendido, é que estando no turno existiria uma maior continuidade pedagógica e com isso maior articulação com o Projeto Político Pedagógico (PPP). Por fim os que defendem as aulas no turno com as demais disciplinas relatam que as aulas quando aconteciam fora do turno tinham características de disciplina extracurricular, o que não era nada interessante. Mas há aqueles que defendem o contra turno se apoiando em argumentos relacionados ao rendimento nas demais disciplinas, pois as aulas de educação física fora do período escolar interferem menos na rotina da escola e, argumentos relacionados à higiene, destacando que a ausência de estrutura física nas escolas dificulta e desestimula os alunos como, por exemplo, não ter vestiários adequados e chuveiros suficientes para atender às necessidades dos alunos que, muitas vezes, retornam à sala de aula suados. Por fim, aqueles que defendem o contra turno acreditam que com as aulas fora do turno conseguiriam otimizar melhor os espaços muitas vezes insuficientes nas escolas. Essa discussão é longa e está longe de alcançar uma unanimidade, mas o retorno da disciplina para o contra turno traria muito mais

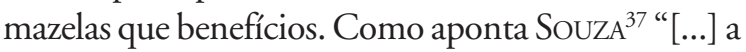
inclusão da educação física no período, junto com as demais disciplinas, proporcionou uma aproximação entre as demais e abriu a possibilidade de se trabalhar a interdisciplinaridade, através do desenvolvimento de projetos" (p.77). As mudanças em relação a essa questão estão presentes nos discursos dos docentes com maior tempo de experiência como S1 e S4, pois para os mais jovens, S2 e S3, essa marca nem aparece como desafio em sua atuação na área, no que se refere às condiçôes de trabalho.

Quanto às condições de trabalho, o que destacamos é que geralmente há nas escolas quadra, materiais diversos como bolas, arcos, cordas etc. A área não se encontra abandonada à própria sorte, tão pouco o docente. Por outro lado, reconhecemos que a organização das práticas muitas vezes depende de uma ação pessoal desse docente. Observamos que ainda falta a consciência e a certeza de que a "escola não é lugar para brincadeira, devemos aprender algo" $\left(\mathrm{SCAGLIA}^{\mathrm{b}}\right)$, e na atual aula de educação física existem inúmeras oportunidades para que isso aconteça.

\section{Núcleo 3: Relação docente-sociedade}

Aqui identificamos nos discursos dos quatro professores a forma como percebem o olhar do outro sobre a educação física, os olhares de alunos, docentes de outras disciplinas, enfim das pessoas em geral, tanto dentro como fora da escola. Os professores investigados explicitaram como esta valorização os atinge, tanto do ponto de vista do universo escolar, incluindo o aspecto econômico, como da área especificamente.

A educação física não tem a mínima importância

para a sociedade. Para o pai e para mãe, ela não tem importância (S1).

Muitas vezes isso se dá em virtude da cultura que esses pais têm e como veem a área diante de suas experiências passadas em seus tempos escolares (S4).

Destacamos que, muitas vezes, os pais possivelmente não reconhecem o valor da área por realmente desconhecerem o que de fato ela é, não reconhecendo a sua relevância na formação de seus filhos. O reconhecimento da educação física enquanto área de conhecimento se concretiza no respeito pelo docente, pelas aulas, pelo espaço que ela ocupa nas escolas: 
Uma sociedade que não reconhece a área [...], portanto não a respeita (S2).

Ainda encontramos com certa força o estereótipo de que a educação física não deve se preocupar em transmitir e/ou construir conhecimento, pois se ocupa apenas da educação do físico. Esta é a sua principal e quase sempre única função. Visões como essas provocam reaçôes:

Ainda hoje se tem a ideia da escola ser um espaço só de educação. Mas quando eu ponho um aluno para correr, [...] que tem marca-passo [...], eu estou usando meus conhecimentos de fisiologia (S3).

A escola ainda pensa no cognitivo e ainda dizem que a educação é global (S3).

Percebemos que a escola ou a comunidade que dela faz parte como já destacamos pais, alunos, docentes de outras disciplinas etc., ainda persistem em visualizar a área como se essa não fosse capaz de participar do processo de ensino-aprendizagem, reforçando um olhar que separa corpo e mente. Assim, a educação física ficaria responsável pela parte educacional do corpo, a parte motora, enquanto a mente, o intelecto, ficaria a cargo dos demais docentes ${ }^{38}$.

Fica claro o incômodo que esse tipo de situação causa em S3. Quando este faz referência à escola como sendo um "espaço só de educação", podemos destacar que se sente desvalorizado, dentro da própria escola, em relação aos seus saberes específicos. De certa forma, se mantém o estereótipo de que o docente de educação física apenas conhece de esportes, jogos e brincadeiras. Como S3 explicita, o docente da área vai além da recreação e tem a possibilidade de transmitir e administrar saberes, que muitas vezes a ele não são atribuídos e sim a outros profissionais. Um docente da área, como demonstrado nas matrizes curriculares das universidades pesquisadas, tem na sua formação inicial conhecimentos que passam pela filosofia, fisiologia, biologia e também pela sociologia, ciências da educação e da história da educação, entre outras áreas disciplinares $^{21}$. Portanto, tem condiçôes de ir além do que se entende por educação física como disciplina técnica desportiva e recreativa.

Na verdade, é importante reconhecer e conscientizarse dos diferentes processos de desenvolvimento que um trabalho pedagógico planejado e intencional nas aulas de educação física pode possibilitar aos alunos nas diversas idades. Tal reconhecimento e conscientização no que se refere à importância dos diferentes aprendizados que as aulas podem proporcionar não acontecem espontaneamente, como parece acreditar S1:

Inicialmente alunos não sabem por que existe a disciplina de educação física. [...] O aluno deveria saber a importância da disciplina, o porquê de alguns conteúdos e aplicá-los na prática (S1).

A área está ligada a um conjunto de conhecimentos com origem nos domínios acadêmicos e por se tratar de um componente curricular, com conteúdos próprios, precisa primeiramente reconhecer os seus objetivos, seus conteúdos, maneiras de ensinar e avaliar, respeitando aspectos históricos e sociais de onde a área esteja inserida ${ }^{39}$.

Como aponta OliveIRA citado por DAOLIO ${ }^{18}$, não será possível obter um desenvolvimento significativo em relação à aprendizagem e muito menos atender os anseios e promover o entendimento dos alunos, sem planejamento e sistematização.

No discurso dos professores entrevistados identificamos marcas de uma educação física que é desvalorizada pelos próprios docentes:

O importante é alfabetizar, ensinar a ler e escrever e fazer contas, isso é o que importa. Todo projeto de reforço gira em torno dessas preocupaçōes. Nunca vi um reforço ou preocupação do tipo: "essa criança cai demais vamos colocá-la em um reforço para melhorar sua coordenação motora" (S3).

Tem professor que "taca" uma bola na quadra e por isso acho que nós mesmos já nos desvalorizamos (S2).

Ao mesmo tempo, há o entendimento que é por meio das açôes dos próprios docentes que se torna possível uma aproximação da comunidade escolar com a educação física, podendo promover uma mudança nas formas como ela é considerada. Para isso precisamos de docentes que valorizem o seu ensino:

Enquanto você não tiver um profissional que convença o aluno disso [relevância] também não vai mudar nunca $(\mathrm{S} 1)$.

Apesar de tal reconhecimento, as marcas no discurso a respeito da liberdade, da descontração são evidentes:

Criança gosta da aula de Educação Física porque não fica dentro da sala (S2).

Os alunos dizem: eu gosto de você! Aí eu brinco com eles: gostam nada, vocês gostam porque eu venho tirá-los da sala, do ambiente fechado e restrito (S3).

Querem ir para educação física para ficar lá fora usufruindo de uma liberdade que não tem em sala de aula com outras disciplinas (S4).

Algumas mudanças em relação à forma como a área vêm se constituindo nos documentos oficiais são evidenciadas no discurso de S4:

Perdeu-se já um pouco aquela história que educação física é só na quadra, não tem que escrever, 
nem aprender sobre nada, hoje já vivemos outro momento na área (S4).

Em resumo, fica evidenciado na fala dos sujeitos que a área ainda não é compreendida pela sociedade de maneira geral (pais e alunos), mas o que ainda surpreende é a falta de entendimento por parte da comunidade escolar (professores e gestores). Muitas dúvidas em relação à legitimidade pedagógica envolvem ainda esta relação entre educação física e sociedade. Para nós o que falta é a percepção por parte das pessoas da relevância da educação física na vida dos alunos dentro e fora da escola. Isso possivelmente se dá pela falta de conhecimentos em relação à área, o que é compreensível, pois não podemos exigir que todos conheçam as suas especificidades. Mas fica claro nos discursos dos sujeitos que em muitos momentos o próprio docente não consegue transmitir o valor da educação física, pois não têm clareza a respeito de seu objeto de conhecimento e de sua identidade, contribuindo para que se mantenha a ideia estereotipada do jogo e da recreação.

Quanto à questão da valorização do professor, um aspecto evidenciado foi o financeiro, que sem dúvida é importante para qualquer categoria profissional. Infelizmente, no campo da Educação não se trata de um problema exclusivo do professor de educação física. Temos que assumir, de uma vez por todas, que tanto na educação física como na Educação de modo geral e também em outras áreas como Medicina, Engenharia existem bons e maus profissionais, interessados ou não, que buscam atualizar-se ou são extremamente acomodados. A busca de melhores condiçóes de trabalho, incluindo as salariais deve fazer parte de um movimento de classe. Mas sem nos esquecermos do nosso papel, pois tem sido reforçado diante de dados extraídos de pesquisas e estudos que nos mostram como limitações econômicas, salários baixos e a falta de valorização e reconhecimento do docente de educação física vêm contribuindo para a diminuição do compromisso deste profissional ${ }^{9}$.

Os dados apontaram que os discursos dos professores entrevistados ainda não incorporaram as concepções mais recentes em relação à educação física, que inclusive figura nas orientações curriculares nacionais e da Secretaria de Educação Estadual de São Paulo.

As propostas que enfatizam a cultura do movimento e a cultura corporal estão ausentes desses discursos e, possivelmente longe das práticas pedagógicas.

A pesquisa realizada destacou que as mudanças tanto no que se refere à legislação, como por exemplo, a partir da LDB/96, instituindo a educação física como componente curricular do Ensino Básico, como as que ocorreram na organização dos cursos de formação inicial em relação ao formato dos cursos, alterando a duração e o perfil do profissional a ser formado, não asseguram uma mudança na forma de ver e compreender a educação física.

Observamos nos discursos dos quatro professores entrevistados sinais de estereótipos que alimentam a visão de uma educação física como lazer ou uma grande diversão, colocando-se acima do conhecimento que se produz. Como decorrência, encontramos a crença de que por ser uma disciplina ministrada, geralmente, na quadras, isso traz grandes facilidades tanto para o desempenho da função docente, como para o fato de se constituir a preferência dos alunos em relação às demais disciplinas. Ainda permanece a ideia de que ter apenas uma bola é suficiente. Não estamos afirmando que essas são, efetivamente, as crenças de nossos sujeitos, mas, suas falas são marcadas por esses estereótipos.

O que se evidenciou foi que o fato de a educação física figurar no imaginário social como uma disciplina livre, contribuiu para influenciar as escolhas de alguns dos sujeitos entrevistados. Por outro lado, constatar a maneira como as famílias, docentes de outras disciplinas e gestores escolares encararam a educação física, consolida um processo de desvalorização da área e, consequentemente, da própria atuação profissional.

Segundo DaOliO ${ }^{10}$

Se, por um lado, existe um discurso dos professores que, em alguns momentos, é transformador e crítico, por outro lado, a lógica de sua prática ainda se mostra arraigada a determinados valores que poderiam ser considerados, precipitadamente, como superados. É dessa forma que a história da educação física no Brasil nos dá bases para entender como os professores reproduzem, no cotidiano, ideais e valores passados, como a higiene e a eugenia do final do século XIX, ou o militarismo nacionalista do Estado Novo, ou o modelo esportivo característico do [...] governo militar (p.43).

Desta forma, esse cenário que marcou os modos de conceber a educação física influenciou as práticas pedagógicas, de maneiras diferentes de sujeito para sujeito. Mas acreditamos que mesmo com mudanças na legislação, mudanças pedagógicas, na organização da formação inicial etc., o que influencia diretamente na área e na valorização da mesma e do docente, ainda está pautada nas ações dentro da escola. $\mathrm{O}$ trabalho coletivo na escola, discutindo, estudando e socializando possibilidades de se consolidar um Projeto Pedagógico coerente, consciente e assumido por todos é fundamental para se pensar em mudanças, possibilitando transformações nas concepções e nas práticas pedagógicas. 


\title{
Notas
}

a. Todas as falas entre aspas e em itálico são de S3.

b. Palestra proferida no 60 Congresso de Educação Física de Jundiaí, 12 nov. 2011.

\begin{abstract}
Physical Education, the teacher and the school: conceptions and pedagogical practices

This article is based on a study which investigated how the changes that took place in the Physical Education area have been marking the teacher's conception and pedagogical practice. It is a qualitative research which investigates four Physical Education teachers who were selected based on the following criteria: working with public education in different schools, and having different under-graduation and teaching time from each other. Data were collected by recurrent interviews. This procedure is based on some interview steps followed by data categorization after each interview. The subjects have an active participation by completing, changing and clearing some information and due to interacting with the researcher. The results enable us to identify that changes which took place in the Physical Education area, from the investigated teachers' point of view, have influenced aspects related to initial formation, the schools' working conditions and also how the pedagogical practice is organized, increasing the value for both the area and the teacher.
\end{abstract}

KEY wORDS: Pedagogical practices; Teachers' formation; Physical education; Recurring interviews.

\section{Referências}

1. Betti M. Perspectivas na formação profissional. In: Gebara A, Moreira WW. Educação física \& esportes: perspectivas para o século XXI. Campinas: Papirus; 1992. (Coleção Corpo \& Motricidade).

2. São Paulo (Estado) Secretaria da Educação. Currículo do Estado de São Paulo: linguagens, códigos e suas tecnologias. São Paulo: SEE; 2010.

3. Oliveira VM. O que é educação física. São Paulo: Brasiliense; 2008. (Coleção primeiros passos; 79).

4. Brasil. Ministério da Educação. Lei de Diretrizes e Bases da Educação Nacional. Lei Federal no 9.394/96. Brasília: MEC: 1996.

5. Hardman K. Physical education within the school curriculum: a beautiful dream? In: Mester J. Sport sciences in Europe 1993: current and future perspectives. Aachen: Meyer \& Meyer; 1994. p.544-60.

6. Marinho I. P. Raízes da educação física no Brasil: II parte. Rev Bras Educ Fís Desportos. 1975;28:16-30.

7. DaMatta R. O ofício de etnógrafo, ou como ter 'anthropological blues'. In: Nunes EO, organizador. A aventura sociológica: objetividade, paixão, improviso e método. Rio de Janeiro: Zahar; 1978.

8. Caparroz FE. Entre a educação física na escola e a educação física da escola: a educação física como componente curricular. 3a ed. Campinas: Autores Associados; 2007.

9. Castellani Filho L. Educação física no Brasil: a história que não se conta. Campinas: Papirus; 1988. (Coleção Corpo \& Motricidade).

10. Daolio J. Cultura: educação física e futebol. 3a ed.rev. Campinas: Editora da UNICAMP; 2006.

11. Brasil. Ministério da Educação e do Desporto. Secretaria de Educação Fundamental. Referencial curricular nacional para a Educação Infantil/ Ministério da Educação e do Desporto, Secretaria de Educação Fundamental. Brasília: MEC/SEF, 1998.

12. Brasil. Ministério da Educação e do Desporto. Conselho Nacional de Educação. Câmara de Educação Básica. Parecer CEB n. 4/98. Diretrizes Curriculares Nacionais para o Ensino Fundamental. Brasília: MEC/CNE; 1998.

13. Brasil. Ministério da Educação e do Desporto. Secretaria de Educação Fundamental. Parâmetros curriculares nacionais terceiro e quarto ciclos do ensino fundamental: introdução aos parâmetros curriculares nacionais. Brasília: MEC/SEF; 1998.

482 • Rev Bras Educ Fís Esporte, (São Paulo) 2013 Jul-Set; 27(3):467-83 
14. Freire JB, Scaglia AJ. Educação como prática corporal. São Paulo: Scipione; 2009.

15. Medina JPS. A educação física cuida do corpo....e "mente". Campinas: Papirus; 2010.

16. Freire JB. Educação de corpo inteiro: teoria e prática da educação física. São Paulo: Scipione; 2009.

17. Soares CL, Taffarel CNZ, Varjal E, Castellani Filho L, Escobar MO, Bracht V. Metodologia do ensino de educação física. 2a ed.rev. São Paulo: Cortez; 2009.

18. Daolio J. Educação física e o conceito de cultura. 3a ed. Campinas: Autores Associados; 2010. (Coleção Polêmicas do nosso tempo).

19. Castellani Filho L. Metodologia do ensino de educação física. 2a ed.rev. São Paulo: Cortez; 2009.

20. Barbosa CLA. Educação física e filosofia: a relação necessária. Petrópolis: Vozes; 2005.

21. Lovisolo H. Educação física: arte da mediação. Rio de Janeiro: Sprint; 1995.

22. Martins MC. A história prescrita e disciplinada nos currículos escolares. Quem legitima esses saberes? Bragança Paulista: EDUSF; 2002. (Coleção Estudos CDAPH. Série História e Ciências Sociais).

23. Góes FT, Mendes CL. Currículo e hierarquia: onde está a educação física? 32a Reunião Anual da ANPED, GT 12: Currículo; 2009; Caxambu, BR. Caxambu: ANPED; 2009.

24. Oliveira MAT, Ranzi SMF. História das disciplinas escolares no Brasil: contribuições para o debate. Bragança Paulista: EDUSF; 2003.

25. Saviani D. Histórias das ideias pedagógicas no Brasil. 3a ed.rev. Campinas: Autores Associados; 2010.

26. Brasil. Ministério da Educação. Secretaria de Educação Média e Tecnológica. Parâmetros curriculares nacionais para o ensino médio. Brasília: MEC/SEMTEC; 2000.

27. Leite SAS, Colombo FA. A voz do sujeito como fonte primária na pesquisa qualitativa: a autoscopia e as entrevistas recorrentes. In: Pimenta SG, Ghedin E, Franco MAS, organizadores. Pesquisa em educação: alternativas investigativas com objetos complexos. São Paulo: Loyola; 2006.

28. Carvalho FLSF. O papel da educação física escolar representado por professores e professoras de outras disciplinas [dissertação]. Juiz de Fora(MG): Universidade Federal de Juiz de Fora; 2006.

29. Sousa ES, Vago TM. A educação física e as Diretrizes Curriculares Nacionais para o ensino fundamental. Presença Pedagog. 1999;5:47-55.

30. Hargreaves A. Teaching and betrayal. Teach Teach: Theor Pract. 2002;8:393-407.

31. Mercado LPL. Formação continuada de professores e novas tecnologias. Maceió: EDUFAL; 1999.

32. Alarcão I, organizador. Escola reflexiva e nova racionalidade. Porto Alegre: ArtMed; 2001.

33. Carrascosa J. Análise da formação continuada e permanente dos professores de ciências. In: Menezes LC, organizador. Formação continuada de professores de ciências no contexto Ibero-americano. Campinas: Autores Associados; 1996.

34. Nunes CMF. Saberes docentes e formação de professores: um breve panorama da pesquisa brasileira. Educ Soc. 2001;22:27-42.

35. Kunz E. Educação física: ensino \& mudanças. 2a ed. Ijuí: Unijuí; 1991. (Coleção Educação Física).

36. Souza NP. A educação física escolar no Estado de Goiás e a formação continuada de professores-realidade e perspectiva [dissertação]. Campinas (SP): Universidade Estadual de Campinas, Faculdade de Educação Física; 2003.

37. Ayoub E. Ginástica geral e educação física escolar. Campinas: Unicamp; 2011.

38. Saviani D. Escola e democracia. 36a ed. Campinas: Autores Associados; 2003.

\section{Agradecimentos}

Apoio CAPES/PROSUP II.

\begin{tabular}{r|l} 
ENDEREÇO & \\
Nestor Bertini Junior & \\
Pontíficia Universidade Católica de Campinas & Recebido para publicação: 01/08/2012 \\
Rod. D.Pedro I, km 136 - Campus I & 1a. Revisão: 28/o8/2012 \\
13086-900 - Campinas - SP - BRASIL & 2a. Revisão: 07/10/2012 \\
e-mail: nbertini@uol.com.br & Aceito: 20/06/2013 \\
&
\end{tabular}

Rev Bras Educ Fís Esporte, (São Paulo) 2013 Jul-Set; 27(3):467-83 • 483 